\title{
Partial Agonist of Benzodiazepine Receptors Ro 19-2088 Elicits Withdrawal Symptoms After Short-Term Administration in Immature Rats
}

\author{
H. KUBOVÁ ${ }^{1}$, P. MARE $\check{S}^{1}$ \\ ${ }^{1}$ Institute of Physiology, Academy of Sciences of the Czech Republic, Prague, Czech Republic \\ Received February 22, 2012 \\ Accepted April 20, 2012
}

\begin{abstract}
Summary
Repeated administration of partial agonist of benzodiazepine receptors Ro 19-8022 (a derivative of quinolizine class) does not elicit withdrawal in adult rats. Our older data demonstrated that single injection of Ro 19-2088 to immature rats induces increased sensitivity to convulsant action of pentylenetetrazol as a withdrawal phenomenon. To know if repeated administration of the partial agonist has the same effect we injected rats at postnatal days 7 to 11 with an anticonvulsant dose of Ro 19-2088 $(0.5 \mathrm{mg} / \mathrm{kg}$ i.p.) and tested them $24 \mathrm{~h}, 48 \mathrm{~h}$ and 4 days after the last injection. Repeated administration of Ro 19-8022 resulted also in an increased sensitivity to convulsant action of pentylenetetrazol in immature rats (higher incidence and severity of seizures). This effect was significant $24 \mathrm{~h}$ after the last injection but only outlined $48 \mathrm{~h}$ after administration. No signs of hypersensitivity were seen at 4-day interval. There is a difference between immature and adult brain in an appearance of withdrawal symptom after administration of the partial agonist of benzodiazepine receptors Ro 19-2088.
\end{abstract}

\section{Key words}

Ro 19-2088 • Iatrogenic withdrawal • Pentylentetrazol-induced seizures $\bullet$ Immature rats

\section{Corresponding author}

Hana Kubová, Institute of Physiology, Academy of Sciences of the Czech Republic, Vídeňská 1083, Prague 4, CZ-142 20, Czech Republic. Fax:+420 24106 2488. E-mail: kubova@biomed.cas.cz
Prolonged analgesia and sedation is frequently used in pediatric intensive care units to provide pain relief and eliminate stress. In pediatric patients opioids are usually co-administered with benzodiazepines, i.e. both with potency to induce dependence, tolerance and withdrawal or abstinence syndromes causing autonomic system dysregulation, motor abnormalities and hyperexcitability of central nervous system, which can exceptionally result in convulsions (Birchley 2009). Available clinical data demonstrate that the risk of withdrawal syndrome depends on length of exposure and in both opioids and benzodiazepines continual administration lasting for 5 days increases the risk of withdrawal to $50 \%$ (Ista et al. 2007). Development of iatrogenic withdrawal can seriously complicate therapy in pediatric patients.

Benzodiazepine receptors are an integral part of central GABAA receptors which bind both benzodiazepine and non-benzodiazepine compounds with different intrinsic efficacy. In full agonists high positive efficacy seems to be related to major therapeutic (anxiolytic, anticonvulsant) but also adverse (sedative) effects. On the other hand, lower intrinsic efficacy in partial agonists may be insufficient to induce unwanted side effects including development of dependence and withdrawal. Partial benzodiazepine agonist Ro 19-8022, a representative of a quinolizinone structure class, showed significant anxiolytic and anticonvulsant effects in both adult (Jenck et al. 1992) and immature (Kubová et al. 1999, Mikulecká et al. 2011) rats. In adult rats, administration of Ro 19-8022 did not induce dependence and development of withdrawal syndrome. In contrast, 
administration of single dose in 12-day-old (P12) rat pups led to rebound increase of seizure susceptibility in pentylenetetrazol (PTZ)-induced seizures. This finding raises question whether immature brain is more prone to development of iatrogenic withdrawal and whether repeated administration of partial agonist causes more severe or longer lasting changes in seizure susceptibility. To answer this question, Ro 19-2088 was injected for 5 consecutive days to P7-P11 rat pups. Time-course of seizure susceptibility changes was tested with threshold dose of PTZ injected up to 4 days after the end of Ro 198022 administration.

Experiment was performed in 45 male Wistar rat pups. The day of birth was counted as zero (P0). Rats were housed in a controlled environment (temperature $22 \pm 1{ }^{\circ} \mathrm{C}$, lights on $0600-1800 \mathrm{~h}$ ) with free access to food and water. Experiments were approved by the Animal Care and Use Committee of the Institute of Physiology of the Academy of Sciences of the Czech Republic. Animal care and experimental procedures were conducted in accordance with the guidelines of the European Community Council directive 86/609/EEC.

Study was performed with partial agonist of benzodiazepine receptors Ro 19-8022 \{(R)-1-[(10-chloro4-oxo-3-phenyl-4H-benzo[a]quinolizin-1-y)carbonyl]-2pyrrolidine-methanol). Drug was suspended in physiological saline with addition of Tween 80 (one drop in $5 \mathrm{ml}$ of saline) and injected intraperitoneally in a dose of $0.5 \mathrm{mg} / \mathrm{kg}$ for 5 consecutive days starting at postnatal day 7 (P7). As documented previously, selected dose of Ro 19-8022 exhibited anticonvulsant effects in PTZ model for more than $12 \mathrm{~h}$ (Kubová et al. 1999). Control animals received saline with a drop of Tween 80.

To assess effects of this short-time exposure to anticonvulsant doses of Ro 19-8022 on seizure susceptibility, PTZ (dissolved in physiological saline $100 \mathrm{mg} / \mathrm{ml}$ ) was injected subcutaneously in a dose of $50 \mathrm{mg} / \mathrm{kg}$. To determine time-course of changes of seizure susceptibility PTZ was injected at three intervals after the end of drug administration: $24 \mathrm{~h}, 48 \mathrm{~h}$ and 4 days. After injection animals were observed for $30 \mathrm{~min}$ and incidence and latency of two types of seizures minimal $(\mathrm{mS})$ and generalized tonic-clonic seizures (GTCS) - were registered (for details see Velíšek et al. 1992).

To assess severity of epileptic phenomena animals were assigned a score for the most severe behavioral characteristics as follows (Pohl and Mareš 1987):
0 - no changes

0.5-abnormal behavior (e.g. automatisms, increased orienting reaction)

1 - isolated myoclonic jerks

2 - atypical or prolonged minimal seizures

3 - minimal clonic seizures

4 - generalized seizures without the tonic phase

5 - complete generalized tonic-clonic seizures

Body weight was daily checked and in order to minimize effects of variability in individual groups, relative body weight was calculated for each measurement (body weight at P7 was taken as $100 \%$ ).

Incidence of either type of seizures was evaluated with Fisher exact test, latencies to seizure onset and seizure severity in drug and appropriate control group at different time intervals were compared with t-test. All data are presented as a mean with standard error of the mean (SEM). The level of statistical significance was set at $P<0.05$, (Sigma Stat $\AA$ software, SYSTAT).

Repeated administration of Ro 19-8022 caused partial growth retardation (Fig. 1). Based on daily measurement experimental animals gained less weight than controls during the treatment period $(\mathrm{p}<0.01)$.

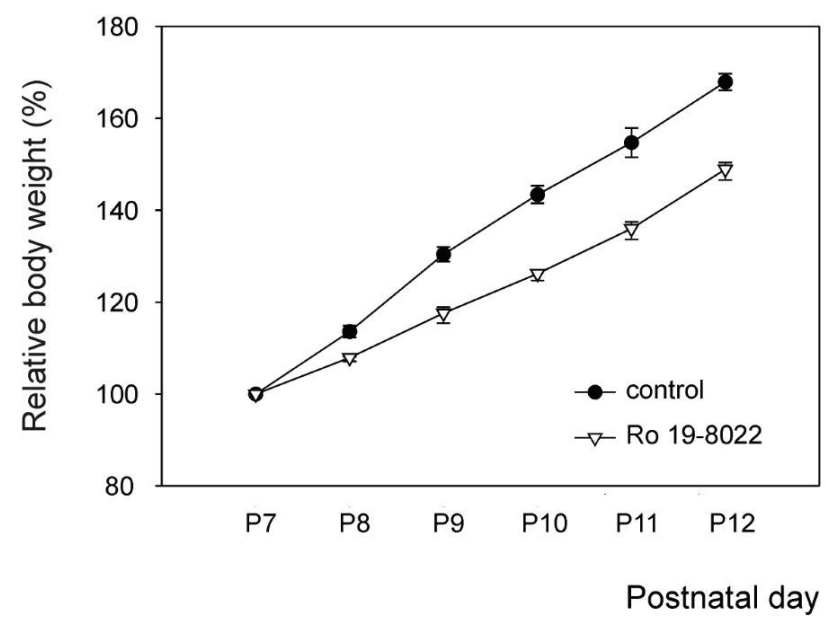

Fig. 1. Relative increase in body weight in control (black dots) and Ro 19-8022-treated animals (empty dots) during treatment period. Abscissa - age in postnatal days $(P)$, ordinate percentage of body weight related to the value before the first injection (P7).

The $50-\mathrm{mg} / \mathrm{kg}$ dose of PTZ elicited $\mathrm{mS}$ in vehicle treated group only exceptionally (Fig. 2). Administration of Ro 19-8022 increased significantly the incidence of $\mathrm{mS} 24 \mathrm{~h}$ after the last injection $(\mathrm{p}=0.032)$. Minimal seizures were observed in 4 of 5 Ro 19-8022treated animals ( $80 \%$ ) in contrast to only one of 8 vehicle 


\section{P7-P11 \\ Ro $19-20880.5 \mathrm{mg} / \mathrm{kg} /$ day}
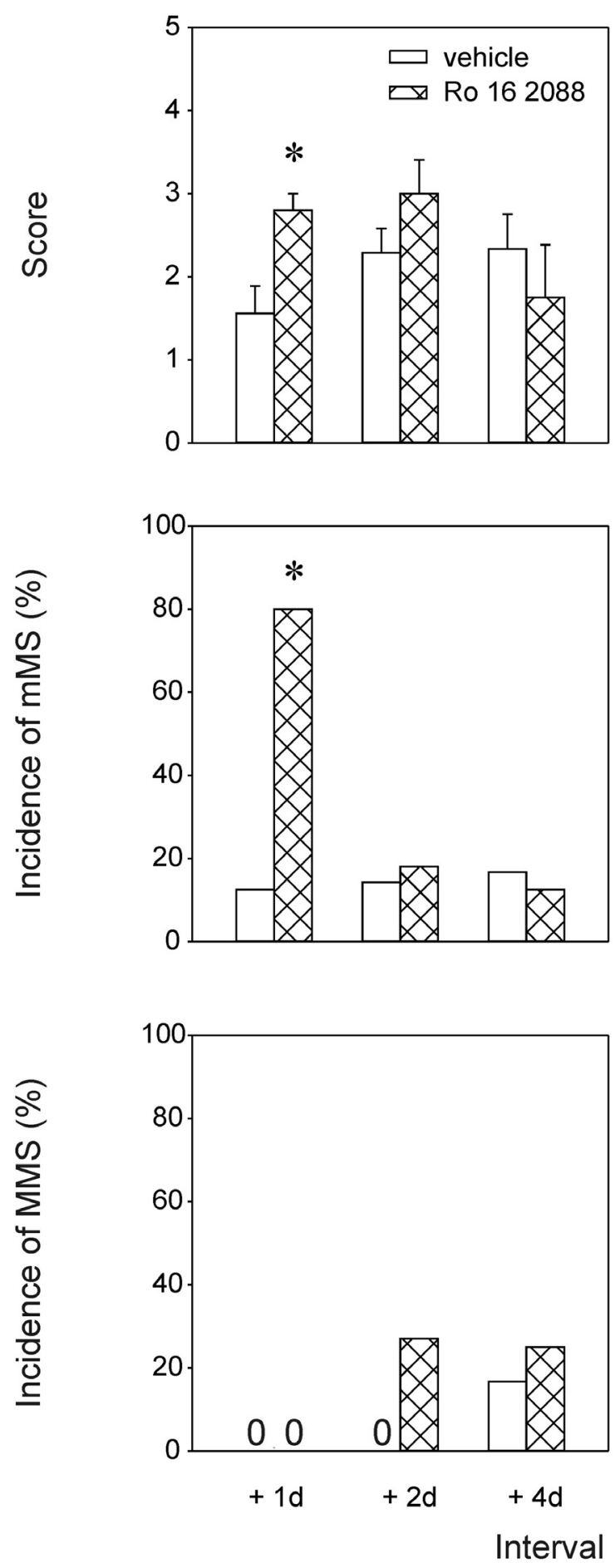

Fig. 2. Seizure severity (upper graph), incidence of minimal clonic seizures (middle graph) and incidence of generalized tonicclonic seizures (lower graph). Abscissae: intervals after the last injection in days; ordinates: upper graph - seizure score; middle and lower graphs - percentage of rats exhibiting seizures. White column denote control groups, hatched columns - experimental rats. Asterisks denote statistical significant difference between control and experimental groups, 0 means that generalized seizures were not present. treated controls $(12.5 \%)$. There was no difference in the incidence of $\mathrm{mS} 2$ and 4 days after the treatment (one control rat of 8 and 6 vs. 2 of 11 and 1 of 8 experimental animals, respectively). GTCS appeared only in one vehicle-treated rat (of 6) 4 days after the end of treatment. Ro 19-8022 administration tended to increase the incidence of GTCS at intervals of $48 \mathrm{~h}$ and 4 days (these seizures were observed in 3 of 11 and 2 of 8 animals, respectively). Differences between control and Ro 198022-treated groups did not reach the level of statistical significance. Severity of seizures was significantly increased in Ro 19-8022 group $24 \mathrm{~h}$ after the administration. The outlined difference at two days after the last injection did not reach the level of statistical significance and at 4-day interval the opposite tendency to lower score in experimental rats was not significant, too (Fig. 2).

Ro 19-2088 is a partial agonist of benzodiazepine receptors with own antagonistic properties comparable with flumazenil. Ro 19-2088 displays only low intrinsic activity (Facklam et al. 1992a) but strong anticonvulsant and anxiolytic properties without motor impairment and sedation in both adult (Facklam et al. 1992b) and immature rats (Kubová et al. 1999). Anticonvulsant effects are dose dependent and in high doses (50 mg/kg and higher) protective efficacy fade away (Kubová et al. 1999). Partial agonists with low intrinsic activity are usually not capable to induce rebound and withdrawal symptoms. In contrast to adult animals (Jenck et al. 1992) immature brain seems to be more prone to development of rebound increase of seizure susceptibility. After single administration of anticonvulsant dose of Ro 19-8022 to 12-day-old rats, sensitivity to threshold dose of pentylenetetrazol was significantly higher than in controls and incidence of minimal seizures was increased $24 \mathrm{~h}$ after drug injection (Mikulecká et al. 2011). In general, risk of iatrogenic withdrawal development is influenced by duration of exposure (Ista et al. 2007). Interestingly, in present study repeated administration did not prolong duration of withdrawal period. In addition, prolonged exposure did not aggravate seizure severity when compared to those after single administration. There are no data on pharmacokinetics of Ro 19-2088 in immature rats and we cannot exclude possibility that repeated administration either leads to cumulation or speeds up elimination of the drug. In previous study we demonstrated that pretreatment with low doses (up to $0.1 \mathrm{mg} / \mathrm{kg}$ ) of Ro 19 2088 increased incidence of minimal seizures in P7 and 
P12 animals after administration of PTZ in a dose of $100 \mathrm{mg} / \mathrm{kg}$ (Kubová et al. 1999). Thus, in case that Ro 19-2088 cumulates in the organisms increased incidence of $\mathrm{mS}$ due to direct effect of tested drug could be confused with withdrawal symptoms. The fact that no differences in seizure incidence or severity occurred in later intervals after the end of treatment however speaks against this possibility.

Longer exposure to effective concentrations of BZR ligands may lead to considerable changes in the number, structure, or function of BZRs and, consequently, to changes of receptor sensitivity. Both benzodiazepine ligands and PTZ act through the same target structure $-\mathrm{GABA}_{\mathrm{A}}$ receptors and some data argue for binding of PTZ to BZRs (Rehavi et al. 1982). The increased sensitivity of BZRs thus may explain the higher susceptibility to PTZ-induced seizures during the withdrawal period. However, receptor alterations were reported after chronic administration of various benzodiazepine ligands except partial agonists such as Ro 19-8022 (Miller et al. 1990).

To conclude, immature brain is more prone than mature one to develop withdrawal symptoms after shortterm administration of partial agonists of benzodiazepine receptors. Whether higher risk of withdrawal symptom is specific only for seizure susceptibility or involves also increased anxiety and other symptoms typically seen after abrupt interruption of benzodiazepine exposure remains to be tested.

\section{Conflict of Interest}

There is no conflict of interest.

\section{Acknowledgements}

This study was supported by grants No. 305/09/0846 and P304/12/G069 of the Grant Agency of the Czech Republic and by Research Project AV0Z 50110509.

\section{References}

BIRCHLEY G: Opioid and benzodiazepine withdrawal syndromes in the paediatric intensive care unit: a review of recent literature. Nurs Crit Care 14: 26-37, 2009.

FACKLAM M, SCHOCH P, HAEFELY WE: Relationship between benzodiazepine receptor occupancy and potentiation of gamma-aminobutyric acid-stimulated chloride flux in vitro of four ligands of differing intrinsic efficacies. J Pharmacol Exp Ther 261: 1106-1112, 1992a.

FACKLAM M, SCHOCH P, BONETTI EP, JENCK F, MARTIN JR, MOREAU JL, HAEFELY WE: Relationship between benzodiazepine receptor occupancy and functional effects in vivo of four ligands of differing intrinsic efficacies. J Pharmacol Exp Ther 261: 1113-1121, 1992 b.

HAEFELY W: Biological basis of drug-induced tolerance, rebound, and dependence. Contribution of recent research on benzodiazepines. Pharmacopsychiatry 19: 353-361, 1986.

ISTA E, VAN DIJK M, GAMEL C, TIBBOEL D, DE HOOG M: Withdrawal symptoms in children after long-term administration of sedatives and/or analgesics: a literature review. "Assessment remains troublesome". Intensive Care Med 33: 1396-1406, 2007.

JENCK F, MOREAU JL, BONETTI EP, MARTIN JR, HAEFELY WE: Ro 19-8022, a nonbenzodiazepine partial agonist at benzodiazepine receptors: neuropharmacological profile of a potential anxiolytic. $J$ Pharmacol Exp Ther 262: 1121-1127, 1992.

KUBOVÁ H, MIKULECKÁ A, HAUGVICOVÁ R, MAREŠ P: The benzodiazepine receptor partial agonist Ro 198022 suppresses generalized seizures without impairing motor functions in developing rats. NaunynSchmiedeberg's Arch Pharmacol 360: 565-574, 1999.

MIKULECKÁ A, MAREŠ P, KUBOVÁ H: Rebound increase of seizure susceptibility but not isolation calls after single administration of clonazepam and Ro 19-8022 in infant rats. Epilepsy Behav 20: 12-19, 2011.

MILLER LG, GALPERN WR, GREENBLATT DJ, LUMPKIN M, SHADER RI: Chronic benzodiazepine administration: VI. A partial agonist produces behavioral effects without tolerance or receptor alterations. J Pharmacol Exp Ther 254: 33-38, 1990.

POHL M, MAREŠ P: Effects of flunarizine on Metrazol-induced seizures in developing rats. Epilepsy Res 1: 302-305, 1987. 
REHAVI M, SKOLNICK P, PAUL SM: Effects of tetrazole derivatives on [3H]diazepam binding in vitro: correlation with convulsant potency. Eur J Pharmacol 78: 353-356, 1982.

VELÍŠEK L, KUBOVÁ H, POHL M, STAŇKOVÁ L, MAREŠ P, SCHICKEROVÁ R: Pentylenetetrazol-induced seizures in rats: an ontogenetic study. Naunyn-Schmiededeberg's Arch Pharmacol 346: 588-591, 1992. 